\title{
ELEGIBILIDADE DAS SOLICITAÇÕES DE REFÚGIO POR MOTIVOS DE ORIENTAÇÃO SEXUAL NO BRASIL.
}

\author{
ELIGIBILITY OF ASYLUM CLAIMS BASED \\ ON SEXUAL ORIENTATION IN BRAZIL. \\ RECONNAISSANCE DES DEMANDES D'ASILE FONDÉES SUR \\ L'ORIENTATION SEXUELLE AU BRÉSIL. \\ ELEGIBILIDAD DE LAS SOLICITACIONES DE REFUGIO POR \\ MOTIVOS DE ORIENTACIÓN SEXUAL EN BRASIL.
}

Vítor Lopes Andrade*

\begin{abstract}
RESUMO: Desde a década de 1980 alguns países começaram a conceder refúgio a solicitantes que tinham o fundado temor de sofrer perseguição em seus países de origem devido às suas sexualidades não-heterossexuais. No Brasil, isso tem acontecido desde 2002. O objetivo deste artigo é analisar a elegibilidade das solicitações de refúgio por motivos de orientação sexual no Brasil, isto é, tentar compreender quais questões são levadas em consideração durante o processo que culmina com o (in)deferimento dessas solicitações. Além de ser utilizada bibliografia específica sobre o tema, foram realizadas entrevistas com advogadas especialistas neste assunto e com funcionários do ACNUR e do CONARE. O governo brasileiro não exige que o país de origem criminalize a homossexualidade a fim de conceder refúgio a solicitantes não-heterossexuais. A perseguição pode ter sido perpetrada - ou o seu temor ser fundamentado - por agente não-estatal; entretanto, parece não haver um posicionamento claro acerca de como se verifica o fundado temor de perseguição no país de origem. No que tange à análise de credibilidade da narrativa, o Brasil apresenta um posicionamento bastante interessante ao fazer uso do critério auto declaratório em relação à orientação sexual; ao mesmo tempo, concepções estereotipadas e ocidentalizadas podem influenciar negativamente a análise.
\end{abstract} ACNUR.

Palavras-chave: Refúgio; Sexualidade; Brasil; Elegibilidade;

* Mestre em Antropologia Social, Universidade Federal de Santa Catarina (UFSC), Florianópolis, SC, Brasil; E-mail: vitorlandrade@yahoo.com.br 
ABSTRACT: From the 1980s, some countries have started to grant asylum to applicants who had the well-founded fear of being persecuted in their countries of origin due to their non-heterosexual sexualities. It has been happening in Brazil since 2002. The objective of this paper is to analyze the eligibility of asylum claims based on sexual orientation in Brazil, that is, to try to understand which questions are taken into consideration during the process that ends with the grant or the denial of the refugee status. Apart from specific bibliography consulted, some interviews were conducted with expert lawyers and with UNHCR's and CONARE's staff. The Brazilian government does not require that the applicant's country of origin criminalizes homosexuality in order to grant asylum to non-heterosexual claimants. Persecutions may have been committed by non-State actors; however, it seems that the government does not have a clear policy of how to check the well-founded fear of persecution in the country of origin. Concerning credibility assessment of the asylum seekers' narrative, Brazil shows a very interesting policy because of the self-identification criterion relating to sexual orientation; at the same time, stereotypes and Western conceptions may influence the decision in a negative way.

Keywords: Asylum; Sexuality; Brazil; Eligibility; UNHCR.

RÉSUMÉ: Depuis les années 1980, certains pays ont commencé à accorder le statut de réfugié aux demandeurs qui craignaient des persécutions dans leur pays d'origine en raison de leurs sexualités non-hétérosexuels. Au Brésil, cela se produit depuis 2002. L'objectif de cet article est d'analyser la reconnaissance des demandes d'asile fondées sur l'orientation sexuelle au Brésil, c'està-dire, d'essayer de comprendre les questions prises en compte au cours du processus qui culmine avec la non reconnaissance de telles demandes. Au delà de la bibliographie spécifique sur ce sujet, des entretiens ont été menées avec des avocats spécialisés et avec le personnel du UNHCR et CONARE. Le gouvernement brésilien n'exige pas que le pays d'origine criminalise l'homosexualité pour d'accorder le statut de réfugié aux candidats non-hétérosexuels. La persécution peut avoir été perpétrée - ou la peur fondée - par un agent non étatique; cependant, il semble que il n'y a pas une position claire sur la façon dont la crainte de persécution fondée dans le pays d'origine est conçue. En ce qui concerne l'analyse de la crédibilité de la narrative, le Brésil a une position très intéressante car il utilise des critères auto-déclaratifs par rapport à l'orientation sexuelle; en même temps, les conceptions stéréotypées et occidentalisées peuvent influencer négativement l'analyse.

Mots-Clés: Refuge; Sexualité; Brésil; Eligibilité; UNHCR. 
RESUMEN: Desde la década de 1980 algunos países comenzaron a conceder refugio a solicitantes que tenían temor justificado de ser perseguidos en sus países de origen debido a orientaciones sexuales no heterosexuales. En Brasil, esto ha estado aconteciendo desde 2002. El objetivo de este artículo es analizar la elegibilidad de las solicitaciones de refugio por motivos de orientación sexual en Brasil. En otras palabras, intentar comprender cuáles son las principales cuestiones tomadas en consideración durante el proceso que culmina con el otorgamiento (o no) de estas solicitaciones. Además de utilizar literatura específica sobre el tema, fueron realizadas entrevistas con abogados especialistas en el asunto y con funcionaros de la ACNUR y de la CONARE. El gobierno brasileño no tiene como condición que el país de origen criminalice la homosexualidad para conceder refugio a los solicitantes no heterosexuales. La persecución puede haber sido realizada -o el temor de ésta ser fundado-por agentes no estatales. Sin embargo, no parece haber una posición clara con relación a cómo se verifica el temor fundamentado de persecución en el país de origen. En lo que refiere al análisis de la credibilidad de las narrativas, Brasil expone un posicionamiento interesante por hacer uso de un criterio de autodeclaración de la orientación sexual. Simultáneamente, concepciones estereotipadas y occidentalizadas pueden llegar a influenciar negativamente el análisis realizado. ACNUR.

Palabras Ilave: Refugio; Sexualidad; Brasil; Elegibilidad;

\section{INTRODUÇÃO}

Desde a década de 1980 alguns países começaram a conceder refúgio a solicitantes que haviam sido perseguidos/as, ou tinham o fundado temor de sofrer perseguição, em seus países de origem devido às suas sexualidades não-heterossexuais. Apesar de não ser um item estipulado na Convenção de 1951, parte-se do entendimento de que aqueles/as que destoam da heterossexualidade podem caracterizar o pertencimento a um grupo social específico, um dos cinco critérios estabelecidos na Convenção. O Brasil tem adotado esse entendimento pelo menos desde 2002, ano do primeiro caso que se tem notícia de refúgio concedido por motivos de orientação sexual.

As pesquisas acadêmicas acerca da orientação sexual como razão do pedido de refúgio começaram a surgir - no mundo e no Brasil - a partir dos anos 2010, sendo que a maior parte da literatura 
se refere à elegibilidade (Venturi, 2017, p. 20), isto é, ao processo de análise do pedido de refúgio. Em âmbito internacional, a primeira obra de referência é o relatório Fleeing Homophobia - Asylum claims related to sexual orientation and gender identity in Europe (Jansen e Spijkerboer, 2011) que discorre sobre elegibilidade em países europeus. No Brasil, Thiago Oliva (2012) publicou o primeiro trabalho sobre o tema em 2012.

O objetivo deste artigo é analisar a elegibilidade das solicitações de refúgio por motivos de orientação sexual no Brasil, isto é, tentar compreender quais questões são levadas em consideração durante o processo que culmina com o deferimento (quando o refúgio é concedido) ou o indeferimento (quando é negado) das solicitações feitas por aqueles/as que chegam ao país em busca de proteção internacional por terem sido perseguidos/as ou por ter o temor de sofrer perseguição em seus países de origem devido às suas sexualidades. Não se trata de um propósito fácil, uma vez que o governo brasileiro não divulga dados oficiais acerca dessas solicitações ${ }^{1}$ :

No que se refere aos dados estatísticos do CONARE, é importante notar que os mesmos passam por atualização contínua. Isso se deve ao fato de que diariamente, o Governo brasileiro recebe novas solicitações de refúgio, assim como periodicamente casos são decididos em reuniões do Comitê. Ademais, a análise estatística do Comitê está em fase de remodelagem, de modo que ainda estamos trabalhando na construção de dados consolidados mais detalhados. Por isso lamentamos não ter, no momento, condições de fornecer dados estatísticos referentes aos refugiados reconhecidos em razão de perseguição por motivo de orientação sexual e identidade de gênero, por se tratar de indicador ainda em construção².

\footnotetext{
1 De acordo com Gabriel Godoy, oficial de proteção do ACNUR, está sendo preparado um relatório - resultante de uma parceria ACNUR-CONARE - sobre as solicitações de refúgio motivadas por orientação sexual no Brasil. Essa informação foi fornecida em setembro de 2016, durante uma palestra no evento "Subjetividades em batalha, territórios em guerra: geopolítica, sexualidade, migração e violência", que aconteceu na UERJ. Até este momento (19 de fevereiro de 2018), entretanto, este relatório ainda não foi divulgado. Dados da sociedade civil acerca das solicitações em razão de orientação sexual nas cidades de São Paulo/SP e Brasília/DF podem ser encontrados em Andrade (2016). 2 Resposta obtida por meio do Sistema Eletrônico do Serviço de Informação ao Cidadão: Ofício ${ }^{\circ}$ 15/2016/SIC CONARE/CONARE/DEEST/SNJ-MJ, de 11 de março de 2016, referente ao pedido de informação ${ }^{\circ} 08850.000543 / 2016-01$.
} 
Além disso, os pareces de elegibilidade não são tornados públi$\cos$ devido à confidencialidade referente às solicitações. Desse modo, a fim de se atingir o objetivo proposto, além de ser utilizada bibliografia específica sobre o tema, foram realizadas entrevistas com três advogadas da sociedade civil especialistas em direitos humanos que atuam ou já atuaram na área do refúgio, com o representante-diretor do Alto Comissariado das Nações Unidas para Refugiados (ACNUR) e com o presidente do Comitê Nacional para os Refugiados (CONA$\mathrm{RE}$ ), órgão do governo brasileiro responsável pelas decisões em primeira instância. Todas as entrevistas foram realizadas no período de janeiro a maio de 2016, durante a pesquisa de campo que fiz na cidade de São Paulo para a minha dissertação (Andrade, 2017).

$\mathrm{O}$ artigo está dividido em três partes. Inicialmente, é apresentada uma contextualização acerca do estatuto dos/as refugiados/ as, discutindo-se a definição do termo, a Convenção de 1951, o Protocolo de 1967 e o critério "grupo social". A segunda parte analisa a lei brasileira de refúgio e o entendimento do CONARE, seguindo as recomendações do ACNUR, de que orientação sexual deve ser entendida enquanto pertencimento a um grupo social específico quando houver perseguição - ou temor - devido a essa razão. Por fim, a terceira parte discorre sobre a elegibilidade das solicitações baseadas em orientação sexual.

\section{CONTEXTUALIZAÇÃO ACERCA DO ESTATUTO DOS/AS REFUGIADOS/AS}

O termo "refugiado" foi definido pela Organização das Nações Unidas (ONU) em 1951 na Convenção Relativa ao Estatuto dos Refugiados $^{3}$. No artigo 1A(2) desta Convenção está disposto que o termo se aplicará a qualquer pessoa

que, em consequência dos acontecimentos ocorridos antes de $1^{\circ}$ de janeiro de 1951 e temendo ser perseguida por motivos de raça, religião, nacionalidade, grupo social ou opiniões políticas, se encontra fora do país de sua

3 Disponível em: http://www.acnur.org/t3/fileadmin/Documentos/portugues/BDL/Convencao_relativa_ao_Estatuto_dos_Refugiados.pdf Acesso em: 16 fev. 2017. 
nacionalidade e que não pode ou, em virtude desse temor, não quer valer-se da proteção desse país, ou que, se não tem nacionalidade e se encontra fora do país no qual tinha sua residência habitual em consequência de tais acontecimentos, não pode ou, devido ao referido temor, não quer voltar a ele. (Artigo 1A(2) da Convenção Relativa ao Estatuto dos Refugiados, 1951).

O período histórico era o do final da Segunda Grande Guerra e, portanto, a definição de refugiado/a estava atrelada àquele contexto, manifestando uma limitação temporal (acontecimentos ocorridos antes de 1951). Essa concepção é alterada no Protocolo de 1967 Relativo ao Estatuto do Refugiado ${ }^{4}$ ao dispor que não se deve restringir o refúgio geograficamente à Europa, tampouco aos acontecimentos decorrentes da Grande Guerra:

§2. Para os fins do presente Protocolo, o termo "refugiado", salvo no que diz respeito à aplicação do $\S 3$ do presente artigo, significa qualquer pessoa que se enquadre na definição dada no artigo primeiro da Convenção, como se as palavras "em decorrência dos acontecimentos ocorridos antes de $1^{\circ}$ de janeiro de 1951 e..." e as palavras "...como consequência de tais acontecimentos" não figurassem do §2 da seção A do artigo primeiro. (Artigo 1 do Protocolo de 1967 Relativo ao Estatuto do Refugiado).

A Convenção estabelece "refugiado" como sendo aquele/a que teme ser perseguido/a em relação a cinco categorias: raça, religião, nacionalidade, grupo social ou opiniões políticas. Nem a Convenção, nem o Protocolo, entretanto, definem o que deve ser entendido por "grupo social”. Isso foi feito de propósito: “[...] percebeu-se que nenhuma definição taxativa, de quem é, ou não, refugiado abarcaria todos os indivíduos, em todas as épocas, que necessitassem dessa proteção [...]" (Jubilut, 2007, p. 132). Trata-se, portanto, de um termo aberto, sem uma definição precisa, que poderia abarcar pessoas que temessem ser perseguidas por uma situação que não se encaixasse nos outros quatro critérios.

4 Disponível em: http://www.acnur.org/t3/fileadmin/Documentos/portugues/BDL/Protocolo_ de_1967_Relativo_ao_Estatuto_dos_Refugiados.pdf Acesso em: 16 fev. 2017. 
Thiago Oliva $(2012$, p. 8) aponta que à época da Convenção a situação mais usual a ser caracterizada como pertencimento a um grupo social era a perseguição a que estavam submetidos proprietários de terras e comerciantes em países socialistas, uma vez que eram tidos pelo Estado como obstáculos à mudança da estrutural social. De acordo com Liliana Jubilut (2007, p. 132), por não ter uma definição exata, grupo social não foi muito utilizado ao longo da história. A autora salienta que essa realidade foi alterada, recentemente, quando se passou a considerar que mulheres e homossexuais devem ser consideradas/os como pertencentes a grupos sociais específicos para fins da concessão de refúgio se seus gêneros/orientações sexuais fazem com que sejam perseguidos/as - ou tenham o fundado temor de perseguição - em seus países de origem.

O posicionamento do ACNUR a esse respeito foi feito em 2002, através da divulgação de dois documentos: "Diretrizes sobre Proteção Internacional n. 01: Perseguição baseada no Gênero no contexto do Artigo 1A(2) da Convenção de 1951 e/ou Protocolo de 1967 relativos ao Estatuto dos Refugiados" (2002a) e "Diretrizes sobre Proteção Internacional n. 02: "Pertencimento a um grupo social específico" no contexto do Artigo 1A(2) da Convenção de 1951 e/ou seu Protocolo de 1967 relativos ao Estatuto dos Refugiados" (2002b).

Nas Diretrizes n. 01, o ACNUR chama a atenção para a necessidade de se levar em conta as dimensões de gênero no que diz respeito ao refúgio, ressaltando que "historicamente, a definição de refugiado tem sido interpretada em um contexto de experiências masculinas [heterossexuais], o que levou ao não reconhecimento de muitas solicitações de mulheres e homossexuais" (ACNUR, 2002a). Dentre as formas de perseguição baseadas em gênero, o documento enuncia atos de violência sexual, mutilação genital feminina, violência doméstica, punições em razão de transgressão de costumes sociais, recrutamento forçado ou enganoso para fins de prostituição/ exploração sexual e discriminação contra homossexuais, transexuais e travestis. Os parágrafos 16 e 17 das Diretrizes n. 01 dizem respeito especificamente à perseguição em razão da orientação sexual de um indivíduo: 
16. Solicitações de refúgio baseadas na orientação sexual contêm um elemento de gênero. A sexualidade ou práticas sexuais do solicitante pode ser relevante para o caso quando ele ou ela tiver sido submetido a uma ação persecutória (inclusive discriminatória) em razão da sua sexualidade ou práticas sexuais. Em muitos desses casos, o solicitante recusou-se a aderir aos padrões ou expectativas de comportamento cultural ou socialmente definidos e atribuídos a cada um dos sexos. As solicitações mais comuns envolvem homossexuais, transexuais ou travestis que enfrentaram a hostilidade pública, violência, abuso ou discriminação grave ou cumulativa. 17. Se a homossexualidade é ilegal em uma sociedade específica, a imposição de penas criminais severas em razão de condutas homossexuais podem configurar uma perseguição, da mesma maneira que configuraria no caso da recusa das mulheres em usar o véu em determinadas sociedades. Mesmo em lugares onde práticas homossexuais não são criminalizadas, um solicitante ainda poderá apresentar uma solicitação de refúgio válida se o Estado é conivente ou tolerante com práticas discriminatórias ou violência perpetrada contra o solicitante, ou quando o Estado é incapaz de protegê-lo de maneira efetiva contra essa violência. (ACNUR, 2002a).

O objetivo das Diretrizes sobre Proteção Internacional do ACNUR é proporcionar orientação legal de interpretação para os/as próprios/as funcionários/as do ACNUR, bem como para governos, tomadores/as de decisão e profissionais do Direito. Assim, no ano de 2002 foram divulgadas também as Diretrizes n. 02, que discutem o "pertencimento a um grupo social específico". O ACNUR aponta, neste documento, não haver uma lista taxativa de quais grupos podem ser vistos como "grupos sociais específicos" e que Estados têm reconhecido mulheres e homossexuais dentro deste critério a fim de conceder o refúgio. Uma explicação importante feita nas Diretrizes n. 02 é que os critérios da Convenção de 1951 não são mutuamente excludentes, isto é, um/a solicitante pode ser elegível como refugiado/a por mais de uma das razões elencadas no artigo $1 \mathrm{~A}(2)$.

No mesmo documento o ACNUR (2002b) evidencia as duas formas como grupo social têm sido interpretado. Para a abordagem da "imutabilidade", um grupo é unido por uma característica imutável ou 
que é tão essencial para a dignidade humana que a pessoa não poderia ser obrigada a renunciá-la. A segunda abordagem é a da "percepção social", segundo a qual o ponto central é a análise acerca de um grupo compartilhar ou não uma característica em comum tornando-o, portanto, identificável como grupo ou o separando da sociedade como um todo. O interessante é que nas Diretrizes n. 02 evidencia-se que mulheres e homossexuais têm sido consideradas/os como um grupo social específico para fins de determinação da concessão do refúgio tanto pela abordagem da imutabilidade quanto pela da percepção social.

Apesar das recomendações do ACNUR datarem de 2002, desde a década de 80 alguns países já vinham concedendo o refúgio por motivos de orientação sexual. De acordo com o relatório Fleeing Homophobia (Jansen e Spijkerboer, 2011), o primeiro caso teria sido na Holanda, em 1981. Oliva (2012, p. 15) aponta para o reconhecimento de um cubano homossexual nos EUA no início dos anos 1990. De acordo com o autor, era habitual que a polícia de Cuba o prendesse arbitrariamente; ele tinha sido enviado a um campo de trabalho forçado e lá permanecido durante dois meses como punição do Estado cubano por ser homossexual.

Foi no ano de 2008 que o ACNUR se posicionou especificamente acerca das solicitações feitas em razão da orientação sexual, dedicando um documento inteiro ao tema. Isso aconteceu através da divulgação da Guidance Note on Refugee Claims relating to Sexual Orientation and Gender Identity (ACNUR, 2008), no qual o termo "homossexual", usado nos dois documentos anteriores (ACNUR 2002a, 2002b), é substituído pelo acrônimo $\mathrm{LGBTI}^{5}$. Um ano antes especialistas de direitos humanos de 25 países haviam lançado os "Princípios de Yogyakarta - Princípios sobre a aplicação da legislação internacional de direitos humanos em relação à orientação sexual e identidade de gênero". Dentre os 29 princípios, o de número 23 se refere ao direito de buscar asilo:

Toda pessoa tem o direito de buscar e de desfrutar de asilo em outros países para escapar de perseguição, inclusive de perseguição relacionada à orientação sexual ou identidade de gênero. Um Estado não

5 Lésbicas, gays, bissexuais, transexuais, travestis e intersexos. 
pode transferir, expulsar ou extraditar uma pessoa para outro Estado onde esta pessoa experimente temor fundamentado de enfrentar tortura, perseguição ou qualquer outra forma de tratamento ou punição cruel, desumana ou degradante, em razão de sua orientação sexual ou identidade de gênero. (Princípios de Yogyakarta, 2007, p. 30).

Ademais, os Princípios acrescentam que os Estados devem assegurar que não sejam discriminados/as aqueles/as que solicitam o refúgio com base em suas orientações sexuais ou identidades de gênero.

A Guidance Note foi substituída em 2012 pelas "Diretrizes de Proteção Internacional n. 09: Solicitações de Refúgio baseadas na Orientação Sexual e/ou Identidade de Gênero no contexto do Artigo 1A(2) da Convenção de 1951 e/ou Protocolo de 1967 relativo ao Estatuto dos Refugiados" (ACNUR, 2012). Trata-se de prática comum por parte do ACNUR substituir suas Guidance Notes, desenvolvidas para responder a necessidades operacionais emergentes, pelas Diretrizes de Proteção Internacional, elaboradas por meio de um processo extensivo (ACNUR, 2008). Em ambos os documentos a definição de orientação sexual utilizada é a dos Princípios de Yogyakarta, referindo-se à

capacidade de cada pessoa de sentir uma profunda atração emocional, afetiva e sexual por pessoas de um gênero diferente do seu, ou do seu mesmo gênero, ou de mais de um gênero, assim como a capacidade de manter relações íntimas e sexuais com essas pessoas. (Princípios de Yogyakarta, 2007, p. 7).

As Diretrizes n. 09 ressaltam que vários países estão conscientes de que as pessoas que fogem de uma perseguição baseada em sua orientação sexual podem ser enquadradas no conceito de refugiado do Artigo 1A(2) da Convenção de 1951, mas afirmam que a aplicação da definição de refugiado ainda não é consistente nesse aspecto. Em relação às diferentes abordagens acerca da interpretação de "grupo social", este documento reforça o posicionamento que o ACNUR tomou desde 2002: 
Aplicando-se qualquer um dos critérios "características permanentes" ou "percepção social", constata-se que existe um amplo reconhecimento de que, havendo uma correta aplicação desses critérios, lésbicas, homens gays, bissexuais e pessoas transgênero são membros de "grupos sociais específicos" no sentido trazido pela definição de refugiado. (ACNUR, 2012, p. 21).

Além disso, as Diretrizes n. 09 salientam que para a abordagem pautada na "percepção social" não é necessário haver um senso de identificação no grupo, não sendo preciso sequer que os membros se reconheçam entre si. $\mathrm{O}$ atributo comum não precisa ser visível a olhou nu nem facilmente identificável pelo público em geral e também "não é necessário ser do conhecimento público quem são os membros específicos do grupo ou quais são as características que eles têm em comum" (ACNUR, 2002, p. 22).

Voltar-se-á às Diretrizes de Proteção Internacional n. 09 abaixo, ao se discorrer sobre a elegibilidade das solicitações de refúgio por motivos de orientação sexual. Agora se faz necessário analisar a lei que definiu os mecanismos de implementação do Estatuto dos Refugiados de 1951 no Brasil.

\section{A LEI BRASILEIRA 9.474/1997}

De acordo com o artigo primeiro da Lei 9.474, sancionada em 22 de julho de 1997, será reconhecido/a como refugiado/a todo indivíduo que

I - devido a fundados temores de perseguição por motivos de raça, religião, nacionalidade, grupo social ou opiniões políticas encontre-se fora de seu país de nacionalidade e não possa ou não queira acolher-se à proteção de tal país;

II - não tendo nacionalidade e estando fora do país onde antes teve sua residência habitual, não possa ou não queira regressar a ele, em função das circunstâncias descritas no inciso anterior;

III - devido a grave e generalizada violação de direitos humanos, é 
obrigado a deixar seu país de nacionalidade para buscar refúgio em outro país. (Brasil, 1997).

Os incisos I e II seguem o disposto na Convenção de 1951 e no Protocolo de 1967, enquanto que o III se refere a uma definição ampliada de refugiado/a, recomendada pela Declaração de Cartagena ${ }^{6}$, um documento elaborado no âmbito da América Latina. A Declaração foi o resultado do "Colóquio sobre Proteção Internacional dos Refugiados na América Central, México e Panamá: Problemas Jurídicos e Humanitários", ocorrido em 1984. Em sua conclusão terceira, consta:

Reiterar que, face à experiência adquirida pela afluência em massa de refugiados na América Central, se toma necessário encarar a extensão do conceito de refugiado tendo em conta, no que é pertinente, e de acordo com as características da situação existente na região [...] Deste modo, a definição ou o conceito de refugiado recomendável para sua utilização na região é o que, além de conter os elementos da Convenção de 1951 e do Protocolo de 1967, considere também como refugiados as pessoas que tenham fugido dos seus países porque a sua vida, segurança ou liberdade tenham sido ameaçadas pela violência generalizada, a agressão estrangeira, os conflitos internos, a violação maciça dos direitos humanos ou outras circunstâncias que tenham perturbado gravemente a ordem pública. (Declaração de Cartagena, 1984, p. 3).

A Lei 9.474 é tida como sendo inovadora, de vanguarda. Isso se deve em especial - mas não só - por incluir essa definição ampliada sugerida pela Declaração de Cartagena (Moreira, 2014, p. 92) sendo vista inclusive como um modelo a ser seguido por outros Estados da América do Sul (Jubilut, 2007, p. 195-196). De acordo com Leão (2007, p. 13), “o tema do refúgio no Brasil, desde a vigência da Lei 9.474/97, passou a ser revestido de um aparato normativo caracterizado por ser um dos mais modernos do mundo".

6 Disponível em: http://www.acnur.org/t3/fileadmin/Documentos/portugues/BD_Legal/Instrumentos_Internacionais/Declaracao_de_Cartagena.pdf Acesso em: 16 fev. 2017.

7 Sobre a inclusão de "grave e generalizada violação de direitos humanos" na lei brasileira, ver Jubilut (2007, p. 134-135). 
No que diz respeito ao refúgio por fundados temores de perseguição em razão da orientação sexual, não há menção explícita na lei brasileira, como há na legislação espanhola, por exemplo ${ }^{8}$. Grupo social, conforme na Convenção de 1951, não é definido pela Lei 9.474. Existe, entretanto, por parte do CONARE - órgão responsável pela análise dos pedidos de refúgio -, a interpretação de que aqueles/ as solicitantes que alegam terem fundados temores de perseguição por motivos de orientação sexual devem ser entendidos/as enquanto pertencendo a um grupo social. O Brasil segue, portanto, as recomendações do ACNUR nessa matéria.

Conforme o Direito Internacional dos Refugiados, a perseguição em virtude da orientação sexual e identidade de gênero é considerada dentro da perspectiva de perseguição por motivo de grupo social. Em linha com a melhor prática internacional, o Brasil também reconhece como refugiados os indivíduos perseguidos por sua orientação sexual e identidade de gênero, amparado pela legislação nacional sobre o tema do refúgio. ${ }^{9}$

Não cabe aqui analisar todos os artigos da Lei $9.474^{10}$, mas se faz importante ressaltar alguns pontos que corroboram para o entendimento de que se trata de uma lei avançada no que concerne ao refúgio.

Em relação ao acesso ao território nacional, o artigo oitavo garante que o ingresso feito de maneira irregular não constitui impedimento para que o/a estrangeiro/a solicite refúgio às autoridades competentes. Assim, não se faz necessário que se tenha, por exemplo, um visto válido a fim de entrar no país legalmente e então solicitar o refúgio.

Uma vez no país, o/a estrangeiro/a solicita o refúgio na Polícia Federal e recebe um protocolo provisório, que lhe dá direito à residência até a decisão final de seu processo (artigo 21). Esse protocolo permite que o/a solicitante tenha CTPS (Carteira de Trabalho

8 Ley 12/2009. Disponível em: https://www.boe.es/diario_boe/txt.php?id=BOE-A-2009-17242 Acesso em: 16 fev. 2017. Acerca de uma análise desta lei, ver Díaz Lafuente (2016).

9 Resposta obtida por meio do Sistema Eletrônico do Serviço de Informação ao Cidadão: Ofício ${ }^{\circ}$ 15/2016/SIC CONARE/CONARE/DEEST/SNJ-MJ, de 11 de março de 2016, referente ao pedido de informação ${ }^{\circ} 08850.000543 / 2016-01$.

10 Para tal, ver Jubilut (2007) e Leão (2007). 
e Previdência Social), expedida pelo Ministério do Trabalho, a fim de exercer atividade remunerada no país (parágrafo primeiro, artigo 21). A permissão para poder trabalhar legalmente antes da decisão final acerca do pedido de refúgio é tida como um dos pontos de inovação da legislação brasileira. Feita a solicitação à Polícia Federal, o caso é encaminhado ao CONARE. Esse Comitê foi criado pela Lei 9.474 (artigo 11), sendo de sua competência, entre outros itens, "analisar o pedido e declarar o reconhecimento, em primeira instância, da condição de refugiado" (artigo 12). A estrutura em que foi estabelecido o CONARE é interessante:

Art. 14. O CONARE será constituído por:

I - um representante do Ministério da Justiça, que o presidirá;

II - um representante do Ministério das Relações Exteriores;

III - um representante do Ministério do Trabalho;

IV - um representante do Ministério da Saúde;

V - um representante do Ministério da Educação e do Desporto;

VI - um representante do Departamento de Polícia Federal;

VII - um representante de organização não-governamental, que se dedique a atividades de assistência e proteção de refugiados no País. $\S 1^{\circ} \mathrm{O}$ Alto Comissariado das Nações Unidas para Refugiados ACNUR será sempre membro convidado para as reuniões do CONARE, com direito a voz, sem voto. (Brasil, 1997).

O Comitê é constituído não só pelos Ministérios e pela Polícia Federal, mas também por um representante de organização não governamental, com poder de voto, e do ACNUR, com direito a voz. Trata-se, portanto, de uma estrutura tripartite (governo brasileiro, sociedade civil e organização internacional), o que é também entendido como sendo inovador na Lei 9.474 (Moreira, 2014, p. 92-93).

O processo de análise do pedido de refúgio é chamado de elegibilidade. O CONARE possui oficiais de elegibilidade, os/as quais fazem entrevistas com os/as solicitantes a fim de verificar se se trata de um caso de refúgio de acordo com o entendimento do Comitê. Nos casos que são deferidos (aprovados), o/a refugiado/a, 
após notificação, dirige-se à Polícia Federal para solicitar a cédula de identidade pertinente (artigo 28), ou seja, o Registro Nacional de Estrangeiros (RNE). Para os casos indeferidos (negados), cabe o direito de recurso ao Ministro de Estado da Justiça, conforme estabelecidos nos artigos 29, 30, 31 e 32 da Lei 9.474 .

A elegibilidade é o ponto central da concessão de refúgio. Nesse sentido, as entrevistas feitas pelos oficiais do CONARE com os/as solicitantes são de extrema importância para o (in)deferimento dos pedidos. São a essas questões que a atenção será agora voltada, especificamente nos casos referentes aos requerimentos por motivos de orientação sexual. Para tanto, além de serem trazidas as perspectivas de três advogadas da sociedade civil especialistas em direitos humanos que atuam ou já atuaram na área de refúgio ${ }^{11}$, do representante-diretor do ACNUR no Brasil e do presidente do CONARE, voltar-se-á às Diretrizes de Proteção Internacional n. 09 do ACNUR (2012). Antes, porém, é preciso ressaltar que o caráter de sigilo em relação às solicitações de refúgio encontra-se estipulado no artigo 25 da Lei 9.474:

Art. 25. Os intervenientes nos processos relativos às solicitações de refúgio deverão guardar segredo profissional quanto às informações a que terão acesso no exercício de suas funções. (Brasil, 1997).

\section{ELEGIBILIDADE DAS SOLICITAÇÕES DE REFÚGIO POR MOTIVOS DE ORIENTAÇÃO SEXUAL}

O primeiro caso que se tem registro acerca da concessão de refúgio em razão de orientação sexual no Brasil data de 2002. Pode ter havido solicitações/reconhecimentos anteriormente, entretanto não se tem informação oficial acerca disso. Renato Leão em seu livro "O reconhecimento dos refugiados pelo Brasil - Decisões comentadas do CONARE" (2007) expõe que em 2002 um casal de colombianos teve seu pedido de refúgio aceito pelo governo brasileiro:

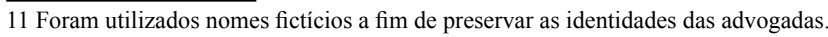


Nos casos dos colombianos, "os mesmos eram provenientes de uma região com forte presença paramilitar onde ocorria a prática da "limpeza social", ou seja, assassinatos seletivos, de caráter propagandista e moralista, que tinham como alvos pessoas consideradas nocivas à sociedade, tais como prostitutas, viciados em drogas, ladrões, menores abandonados e homossexuais. $\mathrm{O}$ caso revelou que os solicitantes, por constituírem um casal homossexual, passaram a sofrer agressões e ameaças por parte de grupos armados que atuavam na região." [Processo n ${ }^{\text {0 }}$ MJ 08495.002602/2002-69]. A ocorrência de assassinatos homofóbicos na localidade justificou o fundado temor dos solicitantes, sobretudo, numa região dominada por grupos que praticam a "limpeza social". Interessante notar que a opção sexual dos solicitantes é irrelevante, já que a perseguição é determinada pela percepção do agente perseguidor. O CONARE deferiu a solicitação de reconhecimento do status de refugiado (Leão, 2007, p. 37-38).

Na análise de Thiago Oliva (2012, p. 21) esse reconhecimento teve duas implicações importantes. A primeira é que não foi considerada como indispensável a criminalização das relações sexuais consentidas entre adultos/as, uma vez que essa punição não existe na legislação da Colômbia. Esse posicionamento está adequado ao que o ACNUR recomendou dez anos depois, em suas Diretrizes n. 09, ao afirmar que o temor a ser perseguido não depende necessariamente da criminalização das relações entre pessoas do mesmo sexo (ACNUR, 2012, p. 14-15). A segunda implicação foi a consideração, por parte do governo brasileiro, de que o Estado não é o único agente responsável pela perseguição: o temor dos colombianos a serem perseguidos foi justificado pela ação de grupos paramilitares. Esse posicionamento também está em consonância com o proposto pelo ACNUR (2012) ao afirmar ser possível reconhecer como perseguição os atos cometidos por atores estatais e não-estatais:

Atores não-estatais, inclusive familiares, vizinhos e a comunidade em geral, podem estar direta ou indiretamente envolvidos em atos persecutórios, o que inclui intimidação, assédio, violência doméstica e outras 
formas de violência física, psicológica e sexual. Em alguns países, grupos armados ou violentos, como, por exemplo, paramilitares, grupos rebeldes, gangues criminosas e agentes fiscalizadores, podem ter como alvo específico indivíduos LGBTI. (ACNUR, 2012, p. 17).

Uma terceira implicação poderia ainda ser vista a partir da afirmação de Renato Leão (2007, p. 38) de que a orientação sexual dos solicitantes seria irrelevante, uma vez que a perseguição foi dada pela percepção do agente perseguidor. Como discutido acima, uma das abordagens de grupo social é aquela que se refere à "percepção social". Desse modo, não é necessário que um indivíduo seja não-heterossexual para ser reconhecido como refugiado por motivos de orientação sexual, desde que o agente perseguidor o identifique enquanto não-heterossexual. A esse respeito, o ACNUR postula:

Indivíduos podem vir a ser submetidos a uma perseguição em razão da sua orientação sexual ou identidade de gênero real ou percebida. A opinião, crença ou filiação podem ser atribuídas ao solicitante por um agente de perseguição do Estado ou não-estatal, mesmo que ele não seja de fato LGBTI, e, com base nessa percepção, eles podem ser perseguidos. Por exemplo, mulheres e homens que não se enquadram nas aparências e papéis estereotipados podem ser percebidos como LGBTI. Não é preciso que eles sejam de fato LGBTI. (ACNUR, 2012, p. 20).

No caso dos colombianos, eles se identificavam como homossexuais e tinham um relacionamento; tratava-se, portanto, de uma orientação não-heterossexual "real". Entretanto, já houve caso de solicitação no Brasil referente à sexualidade "percebida", mas não "real":

Eu me lembro de um rapaz que era casado com mulher, tinha filho. A mulher sofreu uma morte muito violenta, que foi muito traumático para ele. E ele depois disso não conseguiu se relacionar com mais ninguém. A população na região dele começou a persegui-lo dizendo que ele era homossexual. Ele não se considerava homossexual, só dizia que não conseguia se relacionar com mais ninguém, porque 
tinha sido um grande trauma a morte violenta da mulher, do tipo ela foi estuprada por vários homens na frente dele. [...] Ele sequer se identificava como homossexual, mas era perseguido por causa disso. (Trecho de entrevista com Úrsula, advogada da sociedade civil especialista em direitos humanos $-11.05 .2016){ }^{12}$

Há uma heterogeneidade no que diz respeito ao refúgio por motivos de orientação sexual através do critério de grupo social ${ }^{13}$, o que se mostra bastante importante a fim de englobar várias situações nas quais as pessoas não possuem proteção em seus países de origem. Os/ as sujeitos/as que se identificam enquanto gays, lésbicas, bissexuais, homossexuais em países onde as relações consentidas entre pessoas do mesmo sexo são criminalizadas se encaixam nestas solicitações de refúgio; os/as mesmos/as sujeitos/as em países onde essas relações não são criminalizadas, mas que ainda assim possuem fundado temor de serem perseguidos/as em razão de suas orientações sexuais também se encaixam nestas solicitações de refúgio; indivíduos que não possuam desejos/práticas afetivo-sexuais com pessoas do mesmo sexo, no entanto tenham suas orientações sexuais percebidas enquanto não-heterossexuais pelo agente perseguidor também se encaixam nestas solicitações. Por fim, há aqueles/as que possuem desejos por pessoas do mesmo sexo, todavia em seus países de origem, devido ao medo de serem descobertos/as e das consequências penais e/ou sociais que a manifestação de seus desejos traria, não chegaram a ter práticas afetivas ou sexuais, o que não impede que também se encaixem na categoria de refúgio por motivos de orientação sexual. Kelly, advogada da sociedade civil especialista em direitos humanos, afirmou ter atendido um caso destes em São Paulo, de um rapaz que apesar do desejo por pessoas do mesmo sexo não havia manifestado isso em seu país de origem devido à repressão em que vivia. Ele foi reconhecido como refugiado pelo governo brasileiro.

Outro ponto a ser destacado - como já mencionado acima - é que os critérios para a concessão de refúgio não são mutuamente excludentes.

12 A advogada não informou se essa solicitação foi deferida ou indeferida pelo CONARE.

13 Agradeço à professora Dra. Miriam de Oliveira Santos por ter chamado minha atenção a esse ponto durante a $30^{\mathrm{a}}$ Reunião Brasileira de Antropologia, realizada em agosto de 2016, na cidade de João Pessoa. 
Solicitações de refúgio baseadas na orientação sexual e/ou identidade de gênero são comumente enquadradas como parte da razão "pertencimento a um grupo social específico". No entanto, outras razões podem ser aplicáveis, o que vai depender do contexto político, religioso e cultural da solicitação (ACNUR, 2012, p. 19).

Assim uma pessoa pode se enquadrar nos critérios grupo social e opinião política, por exemplo. Foi o caso de um iraniano, conforme analisado por Oliva (2012, p. 24). O solicitante morava em Teerã e participou de manifestações políticas durante a eleição presidencial. Depois desta participação, começou a ser perseguido pela polícia. Sua casa foi invadida e levaram o seu computador. Ao vasculharem o aparelho, descobriram seu relacionamento com outro homem. O iraniano teve então que fugir de seu país e solicitou o refúgio no Brasil, tendo o seu pedido atendido. De acordo com Oliva (2012, p. 24) o reconhecimento se deu por fundado temor de perseguição baseado em pertencimento a grupo social; mas nesse caso houve também a perseguição política, sendo que esta desencadeou a perseguição pela orientação sexual.

Qual é o posicionamento geral do CONARE frente aos casos de solicitação de refúgio por motivos de orientação sexual? Devido à ausência de divulgação de dados estatísticos e pelo fato de que no Brasil os pareceres de elegibilidade não são disponibilizados publicamente $^{14}$, é difícil responder a essa questão. Ademais, o posicionamento pode variar a depender de quem esteja presidindo e de quem esteja coordenando o Comitê em determinado período. Para tentar responder à questão, serão trazidas as visões do ACNUR e da sociedade civil em relação ao posicionamento do CONARE, além da própria fala do CONARE acerca de seu trabalho. Os apontamentos aqui feitos são parciais e incompletos, devido à impossibilidade de se comprovar as falas dos atores em questão; não se pretende, portanto, chegar a conclusões definitivas acerca do posicionamento do CONARE frente às solicitações de refúgio por motivos de orientação sexual. Está consolidado o fato de a orientação sexual ser vista como

14 Há países que divulgam esses documentos em caráter de anonimato, ou seja, sem o nome dos/ as solicitantes ou refugiados/as. 
uma possibilidade de se solicitar o refúgio a partir do critério de pertencimento a um grupo social específico; entretanto, em relação à análise de credibilidade das narrativas e à verificação do fundado temor de perseguição no país de origem - as duas questões centrais para a concessão do refúgio - o cenário se mostra mais complexo.

De acordo com o representante-diretor do ACNUR no Brasil, o CONARE tem garantido a possibilidade de reconhecimento por motivos de orientação sexual desde que o caso esteja bem fundamentado, sendo que essa fundamentação é a mesma exigida nas solicitações baseadas em outros critérios.

Pesquisador: Na visão do ACNUR, qual é o posicionamento do governo brasileiro em relação ao refúgio por motivos de orientação sexual?

Agni Castro-Pita: O governo brasileiro, em geral, estuda com atenção esse tipo de situações e se o caso está fundamentado, até agora não houve nenhum posicionamento de excluir a alguém, deixá -lo excluído da possibilidade de ter esse reconhecimento por motivos de orientação sexual. O que acontece é que o caso tem que estar fundamentado, ter todos os elementos para haver argumentos que facilitem o reconhecimento desta condição.

Pesquisador: E normalmente como é feita essa argumentação?

Agni Castro-Pita: Não há nada adicional nem nada a menos do que se solicita a qualquer pessoa quando tem que argumentar a perseguição por motivos de raça, religião, nacionalidade, opinião política ou pertencimento a grupo social determinado. Seguem-se os mesmo critérios, não se privilegia, mas também não se dificulta.

(Trecho de entrevista com Agni Castro-Pita, representante do ACNUR no Brasil na época - 7 de março de 2016, São Paulo. As respostas foram dadas em espanhol e traduzidas pelo autor).

Beto Vasconcelos - na época secretário nacional de justiça e presidente do CONARE - explicou como é analisado o temor a ser perseguido/a alegado pelos/as solicitantes. Faz-se uma verificação acerca da credibilidade do que é dito pelo/a requerente, em duas esferas: no que diz respeito à situação no país de origem e em relação 
à própria narrativa trazida pela pessoa durante a entrevista com $\mathrm{o} / \mathrm{a}$ oficial de elegibilidade. É preciso, portanto, que se verifique um fundado temor de perseguição devido à situação legal/social no país de origem, sendo necessário, para tanto, que o CONARE tenha informação sobre esse país; de acordo com Beto Vasconcelos, o ACNUR - em virtude de seu poder de voz na composição do Comitê - possui um papel relevante neste aspecto. Também é preciso que a narrativa do solicitante seja coerente, isto é, que sua história seja crível. O presidente do CONARE ressaltou que não se exigem testes acerca da sexualidade da pessoa e que o número de deferimentos dos pedidos por motivos de orientação sexual durante a sua gestão foi maior do que de indeferimentos.

Pesquisador: Da parte dos agentes de elegibilidade, como que eles fazem para verificar - porque a pessoa alega que ela é homossexual e sofreu perseguição ou tinha o temor -, mas como que vai ser julgado se aquilo de fato é um caso por orientação sexual ou não?

Beto Vasconcelos: Primeiro - e por isso a importância de se criar uma base de conhecimento -, pesquisa e referência bibliográfica de órgãos e instituições internacionais que nos esclareçam e tragam informações sobre a situação no país de origem, se há casos documentados e relatados por agências da ONU, por instituições da sociedade civil que atuam globalmente na identificação de violação de direitos humanos, enfim, que tragam informação, consolidem informação sobre o país de origem. "Em um país X ou Y tem acontecido perseguições de tipo A, B, C ou D. [...] Então, ter informação de origem consolidada. Essa é uma das formas e um dos mecanismos que garantem aos nossos oficiais de elegibilidade informação sobre o que acontece naquele país. É uma forma de verificação de credibilidade daquela fala, daquela entrevista. A outra, é a própria entrevista em si. A narrativa apresentada. O detalhamento do histórico da pessoa, a coerência apontada com relação ao histórico regional, ao histórico nacional de seu país de origem e a sua vida privada e o que aconteceu particularmente a sua vida naquela conjuntura. E aí com base no relato, com base na informação sobre o país de origem 
e eventualmente com algum documento - documentos que possam ser juntados pelo próprio solicitante -, esse conjunto de complementação do processo é submetido à plenária do Comitê Nacional para os Refugiados, cuja composição você deve conhecer bem, é plural, com órgãos federais, acompanhamento do ACNUR e com a sociedade civil com poder de voto. O ACNUR com acompanhamento e direito a voz, que muitas vezes nos traz esclarecimentos sobre países em situações específicas, uma vez que eles têm capilaridade em muitos desses países. Esse conjunto de informação é que garante a possibilidade da plenária do CONARE avaliar o caso concreto e aí reconhecer a situação de refúgio, como, por exemplo, motivado por perseguição de orientação sexual. Por óbvio, definitivamente, não há maneiras, e nem haveria de ter outras maneiras que não sejam essas. Ninguém faz teste com relação a isso.

Pesquisador: No Brasil, né, em outros países fazem...

Beto Vasconcelos: É, no Brasil nosso trabalho tem sido com base em informação de origem, informação da narrativa, em credibilidade da narrativa em relação à origem e em relação à sua vida pessoal.

Pesquisador: Você sabe me dizer se das pessoas que solicitam por esse motivo o número de deferimentos ou de indeferimentos é maior? Beto Vasconcelos: Deferimentos é maior. Eu posso lhe dizer o que eu testemunhei de 12 meses. Eu me lembro que dos debates que ocorreram, em grande medida, quase a totalidade dos casos [foram deferidos]. São poucos, perto dos números totais. Mas é maior o deferimento, ou seja, o reconhecimento da situação de refúgio. (Trecho de entrevista com Beto Vasconcelos, secretário nacional de justiça e presidente do CONARE na época - 7 de março de 2016, São Paulo).

Em alguns países são exigidas "provas" acerca da orientação sexual do/a solicitante. Há relatos de que a Inglaterra já pediu que solicitantes lésbicas mostrassem fotos íntimas com suas companheiras a fim de provar sua lesbianidade ${ }^{15}$. Na República Tcheca, até pouco tempo atrás, eram exibidos filmes pornográficos a fim de se realizar testes de excitação com solicitantes homens que alegavam

15 Ver, por exemplo, o relato de Skhumbuzo Khumalo, disponível em: https://www.youtube.com/ watch? $=$ Qz2rodintb0\&feature=youtu.be Acesso em: 19 fev. 2017. 
serem gays ${ }^{16}$. Há relatos também de testes médicos a fim de verificar o ânus de solicitantes homens que afirmam serem gays ${ }^{17}$. Evidentemente, essas formas de se exigir um teste físico, uma prova médica, acerca da orientação não-heterossexual violam os direitos humanos dessas pessoas, além de possuir um entendimento fisiológico da sexualidade, descartando seus aspectos subjetivos (as situações, por exemplo, em que apesar de as pessoas possuírem desejos por outras do mesmo sexo, não manifestaram esses desejos); ao invés de lhes garantir proteção, esses Estados lhes colocam em uma situação de maior violência. Nesse aspecto, o ACNUR é taxativo ao postular que não se devem exigir esse tipo de "comprovações":

O testemunho do próprio solicitante é a primeira e, em geral, a única fonte de provas, especialmente quando a perseguição é feita por membros da família ou da comunidade. [...] Não se deve esperar nem pedir que o solicitante leve provas documentais ou fotográficas de atos íntimos. Também seria inadequado esperar que um casal faça demonstrações físicas durante a entrevista como forma de comprovar a sua orientação sexual.

Testes médicos a respeito da orientação sexual do solicitante violam direitos humanos básicos e não devem ser utilizados. (ACNUR, 2012, p. 31).

O Brasil de fato não exige esse tipo de teste físico em relação às solicitações de refúgio por motivos de orientação sexual, conforme afirmado por Beto Vasconcelos. As advogadas da sociedade civil confirmaram esse ponto. De acordo com Úrsula, "não se pode exigir provas físicas. É na entrevista. Tendo uma entrevista crível. Contando uma história que faça sentido do início ao fim, como foi a perseguição ou porque a pessoa tem medo de sofrer perseguição" (trecho de entrevista com Úrsula, advogada da sociedade civil especialista em direitos humanos). A orientação sexual do solicitante é, portanto, declarada por ele/a mesmo/a. Entretanto, cabe questionar quais são 16 Informação apresentada por Eric Fassin no evento "Subjetividades em batalha, territórios em guerra: geopolítica, sexualidade, migração e violência", no dia 5 de setembro de 2016, na UERJ. Sobre essa temática, ver ORAM (2010).

17 A esse respeito, ver Carlino (2010). 
os critérios de avaliação da credibilidade da narrativa usados pelos oficiais de elegibilidade. A análise de credibilidade está relacionada à ideia de "verdade". Voltar-se-á a essa questão abaixo. Antes, porém, é interessante trazer a fala de Kelly, outra advogada da sociedade civil especialista em direitos humanos, acerca da elegibilidade das solicitações por motivos de orientação sexual.

Pesquisador: Qual tem sido o posicionamento do CONARE em relação aos casos de solicitação baseados em orientação sexual? E como que entra o posicionamento do ACNUR nesse contexto?

Kelly: O posicionamento do ACNUR, os funcionários do ACNUR mantêm uma posição muito "standard" no CONARE, dizendo que se se verifica que há elementos de credibilidade de que a pessoa é homossexual, isso a caracteriza como alguém pertencendo a um determinado grupo social. E, em sendo assim, se em virtude disso, está demonstrado que ela vem sofrendo uma perseguição institucional ou social contra a qual o Estado não consegue proteger a pessoa, a pessoa deve ser reconhecida como refugiada. É o que você lê nos manuais. O CONARE vem sim entendendo que as pessoas que demonstram que sofreram essa perseguição em virtude da orientação sexual são um grupo social e que isso então cumpre com o conceito clássico de refugiado. $O$ debate existe mais na credibilidade da declaração - o que é muito sensível na questão da orientação sexual - e na efetividade da perseguição. Mais recentemente tem esse debate. [...] A questão é quais são os critérios de avaliação de credibilidade da narrativa e qual é o nível de perseguição. Esses dois elementos estão afetando todas as solicitações. Porque, claro, uma situação em que a pessoa venha de um país em que ser homossexual é praticar um tipo penal, isto é, onde há criminalização da homossexualidade, então isso está claro, não tem discussão; o que vai ter discussão é se é crível que a pessoa seja [homossexual], não precisa um ato de perseguição, porque basta que ela declare ser homossexual que ela vai estar sujeita a uma punição criminal. Agora em outras situações, em que não é crime, aí se vê que o que está em disputa é verificar: primeiro, se a pessoa que alega ser homossexual faz isso de maneira 
crível. Não se vai entrar em um âmbito de prova cabal, mas sim de discussão de verossimilhança, de credibilidade, portanto. Sempre vai ter essa discussão: se é crível que a pessoa está narrando que é homossexual, se ela de fato é, ou se é crível que ela seja. E segundo: nos Estados em que não é crime, é preciso verificar também se é crível que ela esteja sujeita a um fundado temor de perseguição. E aí nesse contexto, a equipe atual - não só para a questão do grupo social, dos homossexuais, mas para muitos - a equipe atual tem exigido um nível muito alto de gravidade de fatos já ocorridos que demonstrem que a pessoa tem fundado temor de perseguição. [...] O que se está exigindo é uma gravidade de atos já acontecidos com uma pessoa para se constatar uma perseguição, quando essa perseguição não vem da lei, quando é o caso quando é criminalizada a orientação sexual diversa. É bastante estável o posicionamento do CONARE em relação à questão de orientação sexual, mas essa estabilidade não é segura, não é tão grande quanto se imagina, porque em um caso em que a perseguição não seja uma perseguição institucional vinda da lei, seguindo os padrões que o CONARE tem apresentado, pode-se dizer assim que... Tem um caso, por exemplo, que passou por aqui, um caso reconhecido como refugiado, que o rapaz nunca tinha manifestado socialmente a sua orientação sexual. A repressão é tamanha que ele nunca tinha manifestado. Então, a julgar esse novo parâmetro de avaliação de fundado temor, ele talvez não fosse reconhecido, porque ele não foi submetido a nenhuma ação. A discussão não é somente se eu reconheço que um homossexual pertence a um grupo social ou se ele está sujeito a algum tipo de perseguição ele é um refugiado, em muitos assuntos o que está se exigindo é que a pessoa já tenha sido submetida a algum ato de repressão. (Trecho de entrevista com Kelly, advogada da sociedade civil especialista em direitos humanos - 06.05.2016).

A advogada chama atenção para um ponto central: como se verifica o fundado temor de perseguição? De acordo com ela, estáse exigindo, recentemente, que a pessoa já tenha sido perseguida; portanto, exige-se não só fundado temor, mas uma perseguição in- 
dividualizada a fim de que seja concedido o refúgio. Não há como se chegar a uma conclusão definitiva se isto está acontecendo em relação às solicitações por motivos de orientação sexual, devido à falta de dados oficiais, conforme já ressaltado. Mas se trata de um aspecto crucial. Segundo a Convenção de 1951 e a Lei brasileira 9.474, não é necessário que o/a solicitante tenha sido perseguido/a em seu país de origem. A concepção do estatuto dos/as refugiados/as é justamente proteger as pessoas que têm medo de serem perseguidas. Na análise dos pedidos de refúgio há o elemento subjetivo (temor a ser perseguido) e o elemento objetivo (o que fundamenta este temor); entretanto, não é necessário que o elemento objetivo seja uma perseguição de fato. Por exemplo: um indivíduo não-heterossexual em um país onde as relações entre pessoas do mesmo sexo não são socialmente aceitas, sendo que há assassinatos daqueles/as que não são heterossexuais e a polícia não os protege, ou seja, não há como se recorrer à proteção do Estado, esse indivíduo não precisa esperar que uma perseguição aconteça a ele a fim de fundamentar o seu temor de ser perseguido; a situação em si já fundamenta o temor, não sendo necessário uma perseguição individualizada. A recomendação do ACNUR é acerca da prioridade ao elemento subjetivo:

A perseguição pretérita não é um pré-requisito para o reconhecimento da condição de refugiado e, de fato, o fundado temor de perseguição deve ser baseado na avaliação da situação que o solicitante teria que enfrentar caso fosse devolvido ao seu país de origem. $\mathrm{O}$ solicitante não precisa demonstrar que as autoridades locais tinham conhecimento sobre a sua orientação sexual e/ou identidade de gênero antes da fuga do país de origem. (ACNUR, 2012, p. 11).

Outra grande questão diz respeito à análise de credibilidade da narrativa dos/as solicitantes acerca de suas sexualidades. Fernanda, advogada da sociedade civil especialista em direitos humanos, explica como é feita esta análise durante as entrevistas com os/as oficiais do CONARE: 
O que eles [oficias de elegibilidade] tentam fazer é o que se chama de análise de credibilidade. Então eles vão tentar através de algumas perguntas - não direcionadas para a sexualidade da pessoa, mas direcionadas a outros fatos da vida dela - tentar comprovar ou tentar descontruir a história que a pessoa está apresentando. Então não necessariamente é uma simples narrativa da pessoa, mas ela também vai ser questionada de outros serviços do tipo: se você é homossexual e sabe disso, como é que você conseguiu estar há dez anos no país tendo esse tipo de relação e só agora você precisou sair? [...] A pessoa vai tentar, através de outros fatos da vida dele ou dela, comprovar que aquela história faz sentido ou não faz sentido. (Trecho de entrevista com Fernanda, advogada da sociedade civil especialista em direitos humanos - 01.04.2016).

O fato de não se revelar em um primeiro momento que o motivo - ou um dos motivos - para solicitar o refúgio é o fundado temor de perseguição em razão da orientação sexual pode ser analisado pelos/ as oficiais de elegibilidade como um indício de ausência de credibilidade. É comum que um indivíduo não revele ser não-heterossexual em um primeiro momento - ou que não venha a comentar sobre isso em momento nenhum quando possui outras razões que justifiquem o seu pedido de refúgio -, já que foi a causa que o fez fugir de seu país, depois de anos de repressão, tendo, muitas vezes, sido de fato perseguido por sua orientação sexual. Ao chegar ao Brasil e se deparar com a Polícia Federal, pode ser que o/a solicitante não se sinta confortável em revelar essa informação, com medo de ser discriminado/a por esse órgão, ou por ter que conviver com conterrâneos/as que não sabem acerca de sua sexualidade (e que podem vir a persegui-lo se tiverem conhecimento acerca disso). Na entrevista de elegibilidade - que acontece meses ou anos depois que a solicitação foi feita à Polícia Federal - o/a solicitante pode se sentir confortável em revelar o fundado temor em ser perseguido/a por não ser heterossexual.

Entretanto, ao invés de se refletir sobre o quão difícil pode ser para um indivíduo revelar a uma autoridade policial sobre aquele que foi o motivo pelo qual ele teve que fugir de seu país - tendo sido 
muitas vezes perseguido exatamente pela autoridade policial de seu Estado -, o oficial de elegibilidade pode concluir que o/a sujeito/a está mentindo em uma tentativa de conseguir o refúgio. A questão da "verdade X mentira" é uma constante na elegibilidade, mas há uma "paranoia" em relação às solicitações baseadas em orientação sexual, "paranoia" não encontrada - ao menos não com a mesma intensidade - nas solicitações baseadas em opinião política ou em religião, por exemplo.

Eles [funcionários/as do CONARE] tinham uma preocupação grande, eu lembro que eles levantavam bastante isso, com mentiras. Porque se falava que é um tema muito mais "fácil". Eles brincavam, faziam piadas, do tipo: "é sempre a vizinha do terceiro andar, é a vizinha do terceiro andar que sempre descobre”. [...] Como é um tema muito sensível, às vezes é muito difícil você conseguir: "tá, me conta detalhadamente o que aconteceu". [...] Tinha essa desconfiança. (Trecho de entrevista com Úrsula, advogada da sociedade civil especialista em direitos humanos - 11.05.2016).

Faz-se necessário que os/as oficiais de elegibilidade entendam essa especificidade, esse medo de revelar a orientação sexual, ao invés de taxar a narrativa como ausente de credibilidade. O ACNUR se posicionou a esse respeito:

Discriminação, ódio e violência em qualquer forma podem impactar negativamente a capacidade de o solicitante apresentar a sua solicitação. Alguns solicitantes podem estar profundamente afetados por sentimentos de vergonha, homofobia internalizada e trauma, e sua capacidade de expor seu caso pode ser substancialmente afetada em consequência disto. [...] Não se deve julgar negativamente uma pessoa que não declarou sua orientação sexual ou identidade de gênero na fase da triagem ou nos primeiros estágios da entrevista. (ACNUR, 2012, p. 25).

Ao invés de se encarar o fato da pessoa não ter revelado o temor de perseguição por orientação sexual em um primeiro momento como 
sendo uma "mentira" sobre sua sexualidade, é preciso estar atento aos muitos casos em que as pessoas não revelam isso por medo, podendo, devido ao fato de não mencionar esse fundado temor de perseguição, não serem reconhecidas refugiadas e, portanto, continuarem não gozando de proteção estatal. Mais importante do que eventuais casos de "mentira", faz-se fundamental proporcionar um ambiente em que os/as solicitantes se sintam confortáveis em contar sobre seus desejos e/ou práticas sexuais por/com pessoas do mesmo sexo nos países de origem, deixando claro que não serão estigmatizados/as por isso e expressando o caráter de confidencialidade das informações fornecidas. O ACNUR se posicionou também em relação a isso:

Indivíduos LGBTI precisam de um ambiente favorável ao longo de todo o procedimento de determinação da condição de refugiado, incluindo a pré-triagem, para que eles possam apresentar suas solicitações de maneira completa e sem medo. Um ambiente seguro é igualmente importante durante consultas com representantes legais. (ACNUR, 2012, p. 25).

Um ambiente aberto e que inspire segurança costuma ser crucial para se estabelecer a confiança entre o entrevistador e o solicitante, ajudando-o a expor informações pessoais e delicadas. No começo da entrevista, o entrevistador deve assegurar ao solicitante que todos os aspectos de sua solicitação serão tratados de maneira confidencial. Intérpretes também estão comprometidos com a confidencialidade. (ACNUR, 2012, p. 26).

Outro fator a influenciar na análise de credibilidade diz respeito aos estereótipos envolvendo as sexualidades não-heterossexuais.

A gente [brasileiros/as] já tem uma liberdade de se colocar, gestual, e com eles isso é muito diferente, porque eles têm uma coisa muito mais repreendida, uma auto repressão muito grande. Então, por isso muitas vezes eu acho que confunde o próprio entrevistador, porque o entrevistador ainda acha que a pessoa tem que dar um "vacilo", 
tem que "quebrar uma mão", tem que "quebrar o pescoço", tem que ter a voz mais fina, tem que fazer alguma coisa... E na verdade são pessoas que viveram uma vida inteira dentro de outra realidade e que não vão ter esse tipo de comportamento.

(Trecho de entrevista com Fernanda, advogada da sociedade civil especialista em direitos humanos - 01.04.2016).

O ACNUR alerta que "a presença ou ausência de certos comportamentos estereotipados não devem ser levados em consideração para a conclusão de que o solicitante possui ou não uma determinada orientação sexual" (ACNUR, 2012, p. 26). Concepções estereotipadas - e ocidentalizadas - dos/as oficiais de elegibilidade acerca de desejos, práticas e identidades não-heterossexuais influenciam na análise de credibilidade e podem vir a prejudicar o deferimento das solicitações, conforme já aconteceu no Brasil:

Tem pessoas no CONARE, mas não dá pra dizer que é uma posição do órgão, que são preconceituosas. Não sei se você já ouviu, se alguém já te contou, que tinha um oficial - que não está mais lá agora - que fazia entrevistas e um rapaz contou que era homossexual e aí ele perguntou "ativo ou passivo?". E começou a fazer perguntas totalmente descabidas, colocando a pessoa em uma situação super chata. (Trecho de entrevista com Úrsula, advogada da sociedade civil especialista em direitos humanos - 11.05.2016).

Pode haver um despreparo dos/as oficiais de elegibilidade do CONARE em relação à temática da orientação sexual, como nesse caso relatado por Úrsula. O mesmo episódio já me havia sido narrado por um funcionário do Ministério da Justiça, em meio a uma conversa informal, e também na entrevista com Fernanda. $\mathrm{O}$ funcionário do Ministério me informou que esse oficial havia feito um parecer negativo para o caso em questão, uma vez que o solicitante tinha indicado preferir ser ativo, ou seja, penetrar durante o coito anal. Esse parecer foi questionado; o funcionário foi afastado (também devido a outros motivos, não somente a esse episódio); e o solicitante teve 
o seu pedido deferido posteriormente. De acordo com Fernanda, era recorrente que o oficial de elegibilidade perguntasse sobre as práticas sexuais dos solicitantes por motivos de orientação sexual, sendo que no entendimento dele, os ativos não eram gays "de verdade" e, portanto, não deveriam ser reconhecidos como refugiados.

A atitude desse oficial de elegibilidade suscita vários pontos. O primeiro é como a percepção estereotipada acerca de uma orientação sexual pode prejudicar negativamente na solicitação de refúgio. Para o oficial, há uma associação entre homossexualidade masculina e feminilidade, ou seja, somente aqueles que são penetrados sexualmente (posição associada ao feminino) seriam gays "de verdade". Disso decorre outro ponto: a necessidade de treinamentos sobre gênero e sexualidade para esses/as funcionários do governo ${ }^{18}$. Conforme ressaltado pelo ACNUR, "treinamento especializado nos aspectos particulares da solicitação de refúgio LGBTI para os tomadores de decisão, entrevistadores, intérpretes, advogados e representantes legais é crucial" (2012, p. 26).

Ademais, mostra-se como totalmente inadequado fazer perguntas acerca de práticas sexuais durante uma entrevista de elegibilidade a fim de "comprovar" se uma pessoa é gay ou não:

Explorar elementos que digam respeito às percepções pessoais, sentimentos e experiências de desigualdade, estigmas e vergonha vivenciados pelo solicitante costumam ser mais úteis para o tomador de decisão na determinação da orientação sexual ou identidade de gênero do solicitante, sendo menos útil focar nas práticas sexuais. (ACNUR, 2012, p. 28).

Questões detalhadas a respeito da vida sexual do solicitante devem ser evitadas. Não é um método efetivo de verificar a fundamentação do temor de perseguição do solicitante em razão de sua orientação sexual e/ou identidade de gênero. (ACNUR, 2012, p. 30).

\footnotetext{
18 De acordo com Diego Nardi, assistente de Soluções Duradouras do ACNUR, em 2017 todos/as os/as oficiais de elegibilidade do CONARE receberam treinamentos referentes à orientação sexual realizados pelo ACNUR (informação fornecida durante a Roda de Conversa "Refugiados LGBTQIA+", em 17.11.2017 na cidade de São Paulo, durante a $3^{\text {a }}$ Conferência Internacional [SSEX BBOX] e MIXBRASIL).
} 
Como mencionado anteriormente, pode ser que um solicitante apesar do desejo afetivo-sexual por uma pessoa do mesmo sexo, não tenha tido nenhuma prática sexual; logo, focar nas práticas sexuais ou nas posições preferidas em relação a esses atos decididamente não se mostra adequado nem eficaz para a credibilidade envolvendo as solicitações por motivos de orientação sexual.

Também é inadequado taxar como ausente de credibilidade os pedidos baseados em orientação sexual daqueles/as que foram ou são casados/as com pessoas do sexo oposto, ou divorciados/as, ou que possuem filhos (ACNUR, 2012, p. 29). Seria importante - se possível - analisar qual tem sido o posicionamento do CONARE em relação a solicitantes que possuem desejos e/ou práticas por pessoas do mesmo sexo e do sexo oposto, uma vez que como no caso do oficial de elegibilidade que acreditava que gays ativos não eram gays "de verdade", poderia haver o posicionamento de que bissexuais não seriam perseguidos/as caso manifestassem em seus países de origem somente seu desejo por pessoas do sexo oposto. Não há, entretanto, no momento, como analisar essa questão devido à falta de fontes oficiais. Uma questão importante trazida pelo ACNUR é que não deve ser negado o refúgio a um/a solicitante que tenha dissimulado sua orientação sexual ou sido "discreto" para evitar perseguição ${ }^{19}$ :

O fato de o solicitante poder evitar ou já ter evitado uma perseguição dissimulando ou sendo "discreto" sobre a sua orientação sexual ou identidade de gênero não é uma razão válida para negar o reconhecimento da condição de refugiado. Conforme afirmado em inúmeras decisões de diversas jurisdições, uma pessoa não pode ter o reconhecimento da sua condição de refugiada negado com base na possibilidade de mudar ou esconder a sua identidade, opiniões ou características a fim de evitar uma perseguição. Pessoas LGBTI têm os mesmos direitos de liberdade de expressão e associação que outras pessoas. (ACNUR, 2012, p. 16).

19 O "critério de discrição" tem sido utilizado por alguns países para indeferir os pedidos baseados em fundado temor de perseguição por orientação sexual. A Espanha tinha esse posicionamento até poucos anos atrás, quando uma decisão da União Europeia proibiu que isso fosse feito. A esse respeito, ver Díaz Lafuente (2013). 
A análise de credibilidade passa pela consideração do que é "verdade" em contraposição ao que é "mentira". Não que haja a "verdade" ou a "mentira" em si, mas elas existem na percepção daqueles/ as que trabalham com a elegibilidade. Michel Agier, ao refletir sobre essa questão no que diz respeito às solicitações em geral, afirma que “a suspeita da mentira está sempre presente" (2015, p. 79). Nesse sentido, os questionamentos trazidos por Didier Fassin (2013) em seu artigo The Precarious Truth of Asylum - cuja análise é sobre as solicitações em geral no contexto francês - são interessantes. Para Fassin (2013, p. 18), diferentemente de outras conjunturas nas quais se presume a inocência até que se prove a culpa, os/as solicitantes de refúgio são tratados como suspeitos/as até que provem a sua sinceridade. Portanto, do papel de "vítimas" passam a ser vistos/as como "suspeitos/as". Cabe ao oficial de elegibilidade buscar por erros e contradições; desse modo, o processo de "contar a verdade" se transforma em "detecção de mentira".

Como afirmado acima, há uma "paranoia" das pessoas que trabalham com elegibilidade em relação às solicitações por motivos de orientação sexual serem mais "fáceis", devido à dificuldade de se comprovar uma sexualidade, o que, portanto, necessariamente levaria a que os/as solicitantes se aproveitassem disso, mentindo sobre suas próprias orientações sexuais a fim de conseguir o refúgio. Entretanto, não é fácil se "comprovar" fundado temor de perseguição baseado em religião ou opinião política e mesmo assim não são critérios considerados como sendo "fáceis" de se conseguir o status de refugiado/a. Para alguns, a dificuldade de credibilidade acerca da orientação sexual colocaria em risco a especificidade do refúgio, descaracterizaria esse estatuto, fazendo com que ele perdesse a sua "força". Esse posicionamento encara o deferimento do pedido como sendo a distribuição de um recurso raro, escasso. Mas não se trata de uma escassez material - não há um número máximo de solicitações que podem ser deferidas -; trata-se de uma escassez simbólica (Fassin, 2013, p. 19).

The paradox is that, to justify this suspicion, one has to overestima- 
te the value of asylum. Is is because officers and magistrates regard the status of refugee as an almost unattainable goal that it becomes normal to exclude the great majority of claimants, who are viewed as unworthy of it (Fassin, 2013, p. 10).

Há, portanto, uma questão do valor que é atribuído ao estatuto de refugiado/a: deve ser um recurso escasso, não pode estar ao alcance de todos/as, o que faz com que muitos casos sejam considerados como ausentes de credibilidade. Para Fassin (2013, p. 21), a credibilidade, na verdade, depende mais da pessoa que ouve do que da história que é contada. Desse modo, uma narrativa ser crível ou não pode depender mais da percepção pessoal do oficial de elegibilidade acerca do que ele/a ouviu, do que dos fatos em si.

\section{CONSIDERAÇÕES FINAIS}

As considerações aqui feitas acerca do posicionamento do CONARE frente às solicitações de refúgio por motivos de orientação sexual foram parciais e incompletas devido à ausência de dados oficiais que permitam chegar a "conclusões" sobre a temática. Através das fontes disponíveis, o que se pode apontar é que apesar de a Lei 9.474 não se referir explicitamente à orientação sexual, está consolidada no CONARE a possibilidade de concessão de refúgio através do critério "grupo social" àqueles/as solicitantes que tinham fundado temor de perseguição por motivos de orientação sexual em seus países de origem.

No que diz respeito à elegibilidade, o governo brasileiro não exige que o país de origem criminalize a homossexualidade a fim de conceder refúgio a solicitantes não-heterossexuais. Ademais, a perseguição pode ter sido perpetrada - ou o seu temor ser fundamentado - por agente não-estatal, como no caso dos colombianos que foram reconhecidos refugiados em 2002.

Não há um posicionamento claro acerca de como se verifica o fundado temor de perseguição no país de origem: ao mesmo tempo em que houve o reconhecimento de um solicitante que não havia 
chegado a manifestar sua orientação não-heterossexual em seu país de origem devido ao medo de ser descoberto, há indicações de advogadas da sociedade civil de que ultimamente parece estar se exigindo uma perseguição prévia a fim de se conceder o refúgio. Desse modo, infere-se que o posicionamento do CONARE em relação a esse item pode variar a depender de quem esteja presidindo e de quem esteja coordenando o Comitê em determinado período ou mesmo de acordo com o entendimento de cada oficial de elegibilidade.

No que tange à análise de credibilidade da narrativa, o Brasil apresenta um posicionamento bastante interessante ao fazer uso do critério auto declaratório em relação à orientação sexual e por não exigir "testes" físicos ou médicos. Ao mesmo tempo, concepções estereotipadas e ocidentalizadas podem influenciar negativamente a análise, como no caso do oficial de elegibilidade - posteriormente afastado - que fazia perguntas acerca das práticas sexuais dos solicitantes e não considerava gays ativos como sendo gays "de verdade".

\section{REFERÊNCIAS}

ACNUR. Diretrizes sobre proteção internacionaln. 01. Perseguição baseada no Gênero, no contexto do Artigo 1A(2) da Convenção de 1951 e/ ou Protocolo de 1967 relativos ao Estatuto dos Refugiados. 2002a. Disponível em: http://www.acnur.org/fileadmin/Documentos/ BDL/2014/9738.pdf?view=1. Acesso em 22 de novembro de 2016.

. Diretrizes sobre proteção internacional n. 02. "Pertencimento a um grupo social específico" no contexto do Artigo 1A(2) da Convenção de 1951 e/ou seu Protocolo de 1967 relativos ao Estatuto dos Refugiados. 2002b. Disponível em: http://www.acnur.org/t3/ fileadmin/Documentos/BDL/2014/9741.pdf?view=1. Acesso em 22 de novembro de 2016.

. Guidance note on refugee claims relating to sexual orientation and gender identity. 2008. Disponível em: http://www.refworld.org/ docid/48abd5660.html. Acesso em 22 de novembro de 2016.

. Diretrizes sobre proteção internacional $n$. 09. Solicitações de Refúgio baseadas na Orientação Sexual e/ou Identidade de Gênero no contexto do Artigo 1A(2) da Convenção de 1951 e/ou Protocolo de 1967 relativo ao Estatuto dos Refugiados. 23 de outubro de 2012. Disponível em: http://www.acnur.org/t3/fileadmin/Documentos/ BDL/2014/9748.pdf?view=1. Acesso em 22 de novembro de 2016. 
AGIER, M. Encontros etnográficos. Interação, contexto, comparação. 1. ed. São Paulo: Editora Unesp; Alagoas: Edufal, 2015.

ANDRADE, V. L. Refúgio por orientação sexual no Brasil: perfil das solicitações nas cidades de Brasília/DF e São Paulo/SP. Revista do Núcleo de Estudos e Pesquisas em Gênero \& Direito (UFPB), v. 5, p. 1-24, 2016.

Imigração e Sexualidade: solicitantes de refúgio, refugiados e refugiadas por motivos de orientação sexual na cidade de São Paulo. 2017. 238 p. Dissertação (Mestrado em Antropologia Social) - Universidade Federal de Santa Catarina, Programa de PósGraduação em Antropologia Social, Florianópolis, 2017.

BRASIL. Presidência da República. Casa Civil. Lei n. 9.474, 22 de julho de 1997. Define mecanismos para a implementação do Estatuto dos Refugiados de 1951. Brasília, DF, 1997.

CARLINO, R. Objectivity, authority, and truth: confirming a homosexual identity in lesbian and gay fights for asylum. Peace Studies 2010 Conference. Disponível em: file:///C:/Users/Windows\%207/ Downloads/grinnell-168.pdf. Acesso em 22 de novembro de 2016.

DÍAZ LAFUENTE, J. Estudio de la doctrina jurisprudencial española sobre la protección internacional por motivos de orientación sexual e identidad de género. In: FABADO, Isabel (org.). Libertad de circulación, asilo y refugio en la Unión Europea. Valencia: Tirant lo Blanch, 2013. . Asilo y refugio por motivos de orientación sexual e identidad de género. Madrid: Cuadernos del Congreso de los Diputados 14, 2016.

FASSIN, D. The Precarious Truth of Asylum. Public Culture, v. 25, n. 1, p. 39-63, 2013.

JANSEN, S.; SPIJKERBOER, T. Fleeing Homophobia. Asylum claims related to sexual orientation and gender identity in Europe. COC Netherlands and VU University Amsterdam. Setembro de 2011.

JUBILUT, L. O Direito internacional dos refugiados e sua aplicação no ordenamento jurídico brasileiro. São Paulo: Editora Método, 2007.

LEÃO, R. O reconhecimento dos refugiados pelo Brasil - decisões comentadas do CONARE. ACNUR Brasil e CONARE, 2007.

MOREIRA, J. Refugiados no Brasil: reflexões acerca do processo de integração local. REMHU-Rev. Interdiscip. Mobil. Hum., Brasília, ano XXII, n. 43, p. 85-98, 2014.

OLIVA, T. Minorias Sexuais enquanto 'Grupo Social' e o Reconhecimento do Status de Refugiado no Brasil. Brasília: ACNUR Brasil (Diretório de Teses de Doutorado e Dissertações de Mestrado do ACNUR), 2012.

ORAM (Organization for Refugee, Asylum \& Migration). Testing Sexual 
Orientation. A scientific and legal analysis of plethysmography in asylum \& refuge status proceedings. Dezembro de 2010.

PRINCÍPIOS DE YOGYAKARTA. 2007. Disponível em: http://www. clam.org.br/pdf/principios_de_yogyakarta.pdf. Acesso em 22 de novembro de 2016 .

VENTURI, D. Reflections on empirical research with LGBTI refugees - a legal scholar's perspective. Oxford Monitor of Forced Migration, v. 6, n. 2, p. 20-21, 2017. 